R. P. Frutos,* T. G. TAMPOnE, J. A. MUlder, S. ROdRigueZ, N. K. YEE, B.-S. YANG, C. H. SENANAYAKE (BOEHRINGER INGELHEIM PHARMACEUTICALS, RIDGEFIELD, USA) Development of a Practical Process for the Synthesis of PDE4 Inhibitors Org. Process Res. Dev. 2016, 20, 982-988.

\title{
Synthesis of PDE4 Inhibitors
}
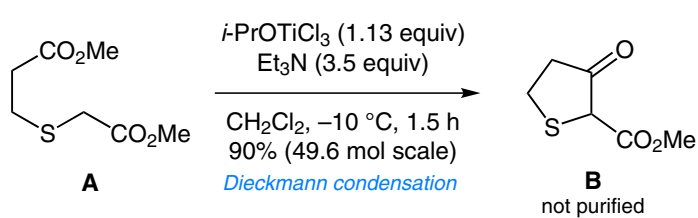<smiles>Clc1nc2c(c(NC3CCOCC3)n1)SCC2</smiles>

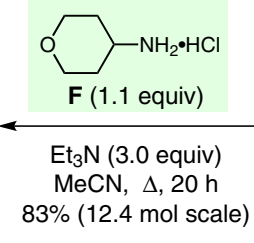

mp not reported<smiles>Clc1nc(Cl)c2c(n1)CCS2</smiles>

$\mathrm{mp}$ not reported

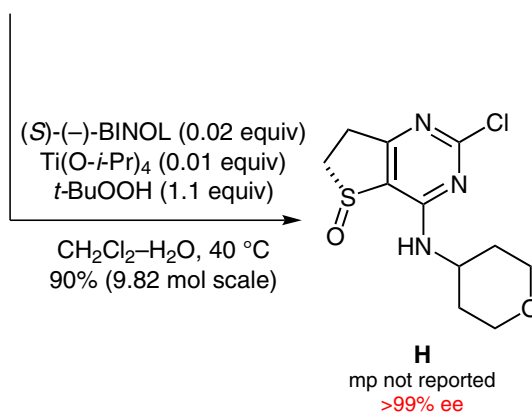

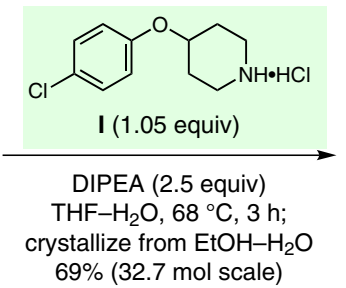

$69 \%$ (32.7 mol scale)
Significance: The target phosphodiesterase type 4 (PDE4) inhibitor $\mathbf{J}$ is of interest for the treatment of chronic obstructive pulmonary disease. The multikilogram-scale synthesis depicted features a highly regioselective Dieckmann condensation $(\mathbf{A} \rightarrow \mathbf{B})$ required for the construction of the dihydrothieno[3,2- $d$ ] pyrimidine $\mathbf{D}$ and the asymmetric sulfoxidation of intermediate $\mathbf{G}$ using the conditions of Uemura and co-workers (J. Org. Chem. 1993, 58, 4529).
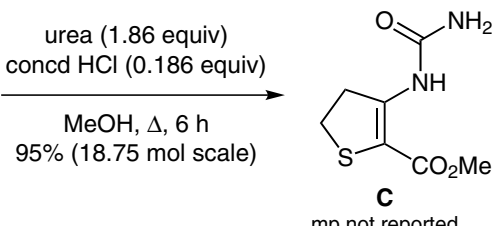

$\mathrm{mp}$ not reported

$$
\begin{array}{r}
\mathrm{NaOH}(1.0 \text { equiv }) \\
\mathrm{H}_{2} \mathrm{O}, 85^{\circ} \mathrm{C}, 3 \mathrm{~h} \\
95 \%(9.47 \text { mol scale })
\end{array}
$$

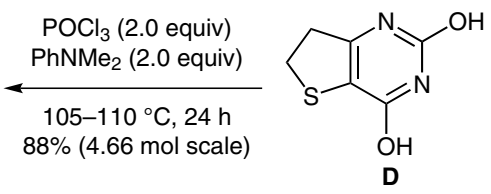

mp not reported

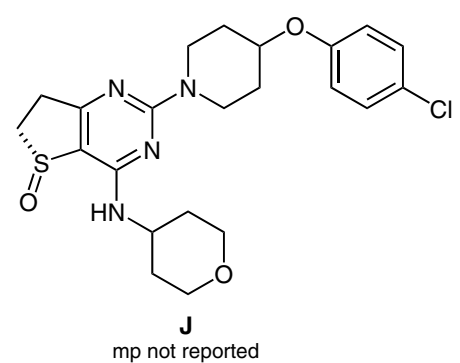

Gategory

Synthesis of Natural

Products and

Potential Drugs

\section{Key words}

phosphodiesterase type 4 inhibitors

\section{Dieckmann} condensation

\section{asymmetric} sulfoxidation

Comment: The transformation $\mathbf{E} \rightarrow \mathbf{G}$ was accompanied by $15 \%$ of the product resulting from displacement of the chlorine at C2. Investigation of alternative bases and solvents failed to improve the regioselectivity; however, the undesired regioisomer was significantly more soluble than $\mathbf{H}$ and was completely removed from the product during the isolation by filtration. 